\title{
Calcific lesion preparation for coronary bifurcation stenting
}

\author{
Matteo Perfetti ${ }^{1}$, Fabio Fulgenzi ${ }^{2}$, Francesco Radico ${ }^{2}$, Alessandro Toro ${ }^{2}$, \\ Antonio Procopio ${ }^{2}$, Nicola Maddestra ${ }^{2}$, Marco Zimarino, ${ }^{1,2}$ \\ ${ }^{1}$ Interventional Cath Lab, ASL 2 Abruzzo, Chieti, Italy \\ ${ }^{2}$ Institute of Cardiology “G. d'Annunzio University”, Chieti, Italy
}

\begin{abstract}
Bifurcating coronary lesions are a very common challenge in interventional cardiology because of the technical complexity in their treatment, the risk of side branch occlusion and an overall worse outcome when compared to non-bifurcating lesions.

The presence of calcifications represents further complexity due to the difficulty in device delivery and stent expansion as well as enhanced risk of side branch occlusion.

Rotational and orbital atherectomy, scoring and cutting balloons, coronary lithoplasty are available tools which have been introduced over the last three decades to overcome such issue. Nevertheless, their application in different contexts of bifurcations presents specific caveats and the studies directed at comparing such techniques have never been expressly oriented in the subset of the bifurcating lesion.

In this paper, we review these devices and their usefulness in bifurcations by analyzing consistent data from clinical trials, and we propose a practical algorithm for the treatment of severely calcified bifurcating lesions according to their anatomical features. (Cardiol J 2019; 26, 5: 429-437)
\end{abstract}

Key words: bifurcation, calcified lesion, plaque modification, rotational atherectomy, coronary lithoplasty

\section{Introduction}

Bifurcating coronary lesions are a very common challenge for interventional cardiologists because of the technical complexity in their treatment, a higher risk of procedural complications and an overall worse outcome compared to nonbifurcating lesions [1]. The inherent difficulty of bifurcation percutaneous coronary intervention (PCI) stems from the risk that main vessel (MV) stenting may hamper flow in the side branch (SB).

The European Bifurcation Club (EBC) consensus document recommends a single "provisional" stenting technique, although acknowledging that bifurcations with diffuse SB involvement often requires double stenting [2]. Several stent techniques have been developed in order to tailor double stent deployment to the complex anatomy of the bifurcation. Hence, significantly higher risk of myocardial infarction and stent thrombosis have been associated with double when compared with single stenting [3].

In this scenario, the main issues to effectively guarantee optimal vessel patency are prevention of plaque shifting and careful carena reconstruction; further complexity may be due to calcification that increases the risk of SB occlusion or hampers crossability or adequate lesion dilatation [4].

Various strategies have been tested in order to prepare the plaque in the bifurcation and to reduce or displace the amount of calcium before stenting, and the inherent scientific literature presents a consistent controversy. The aim of this paper is to review current strategies adopted to modify calcific plaque before stent deployment in coronary bifurcations.

Address for correspondence: Marco Zimarino, MD, PhD, Cath Lab and Institute of Cardiology, "G. d'Annunzio" University, SS. Annunziata Hospital, Via dei Vestini, 66013 Chieti, Italy, tel: +39-0871-41512, fax: +39-0871-402817, e-mail:m.zimarino@unich.it

Received: 12.02.2019 Accepted: 4.07.2019 


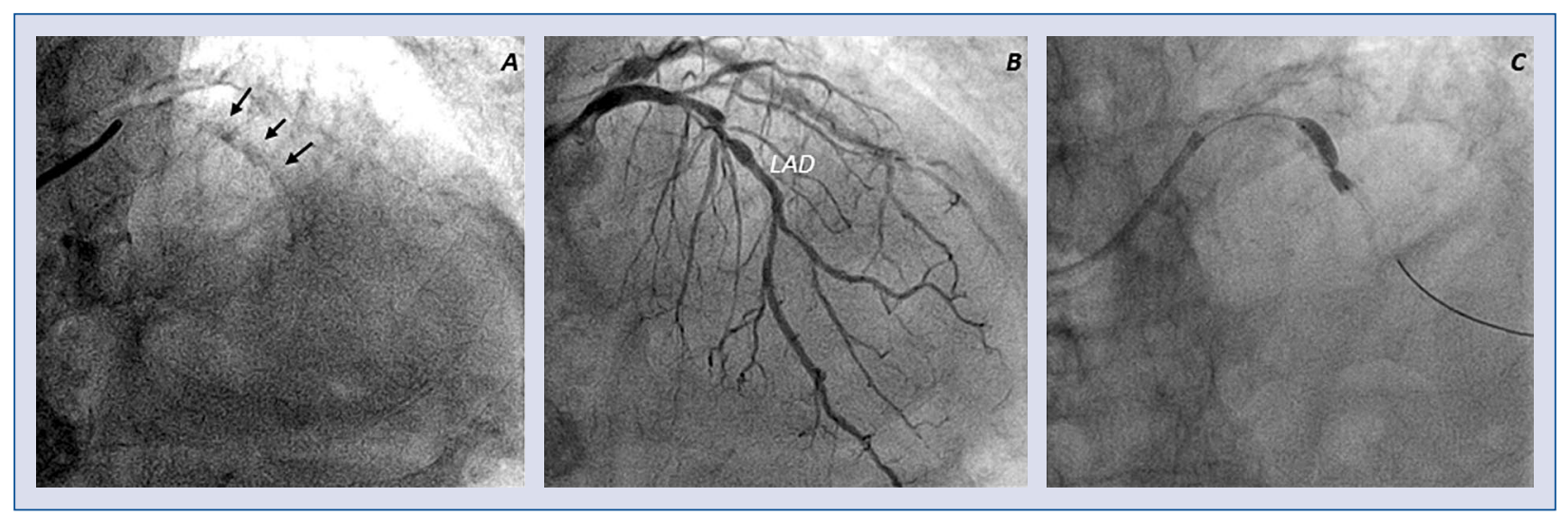

Figure 1. Coronary calcified bifurcating lesion. Diffuse calcifications of left anterior descending artery (LAD); A. Fluoroscopy view (arrows indicate calcifications) of LAD; B. Angiographic view; C. Fluoroscopy view of incomplete balloon expansion.

Table 1. Calcium quantification by imaging modality.

\begin{tabular}{ll}
\hline Angiography & $\begin{array}{l}\text { Radio-opacities before contrast injection noted with cardiac motion } \\
\text { (moderate), or without cardiac motion (severe) }\end{array}$ \\
Optical coherence tomography & $\begin{array}{l}\text { Signal-poor with sharply delineated leading, quantified by thickness } \\
\text { (mild }<0.5 \mathrm{~mm} \text {; severe }>0.5-1 \mathrm{~mm} \text { ), area, and volume }\end{array}$ \\
Intravascular ultrasound & $\begin{array}{l}\text { Hyperechoic leading edge with acoustic shadowing, quantified mainly } \\
\text { by angle (concentric if }>270^{\circ} \text { ) and length }\end{array}$ \\
\hline
\end{tabular}

\section{Calcification at bifurcating lesions}

When dealing with a bifurcation lesion, the first issue should be an assessment of the relevance of the SB; in this view, Kim et al. [5] clearly documented that a length $\geq 73 \mathrm{~mm}$, not the diameter of the SB, identifies a vessel supplying a "significant" portion of myocardium, notably a fractional myocardial mass $\geq 10 \%$.

Hence, following a widely accepted classification by Medina et al. [6], SB plaque involvement should be checked. The so called "true bifurcations" define lesions where plaque enters the SB, namely Medina $1,1,1-1,0,1-0,1,1$, although there is growing evidence that not the sole SB involvement, but $\mathrm{SB}$ lesion length $>9 \mathrm{~mm}$ is an independent predictor of adverse events [7].

The use of intravascular imaging is of great value to ascertain the distribution of the plaque, the true vessel size and the extent of calcium in bifurcating lesions, even beyond the bifurcation of the left main (LM) [8], that is currently the only site where guidelines recommend the use of intravascular ultrasound (IVUS) [9].

Extensive calcification is the main determinant of balloon and stent underexpansion during PCI (Fig. 1) [10]. The sensitivity of intravascular imag- ing is far higher than angiography in detecting coronary calcifications, as angiography is able to detect a calcified plaque only for calcium angles almost $>100^{\circ}$, by either IVUS or optical coherence tomography (OCT). Nevertheless, all disagreement between the angiography and intravascular imaging is related to thin calcifications that have not been shown to affect stent expansion (Table 1) [4]. Even with the availability of newer drug-eluting stents (DES), patients with severely calcified lesions still have worse clinical outcomes compared with those without [11]. Clinical relevance of coronary calcification cannot be neglected, as treating stent underexpansion in a heavily calcified lesion is more difficult than preventing it [12]. However, although there is general agreement that the greater the arc length, or thickness of calcium, the greater the likelihood of stent underexpansion, there are no published cutoffs that can be used for recommending lesion modification prior to stent implantation or the need for high-pressure adjunctive balloon inflations afterward.

The presence of extensive calcification at the site of bifurcation evaluated by OCT portends a higher risk of occlusion of the side branch, as documented by Fuijino et al. [4]. In multivariate analysis, the presence of a calcified plaque in 
the bifurcation segment of MV (odds ratio [OR]: 12.32; 95\% confidence interval [CI]: 2.58-58.83; $\mathrm{p}=0.002)$ as assessed by OCT was the most relevant feature associated with SB deterioration, being bifurcation angle $>70^{\circ}$ (OR: $11.83 ; 95 \% \mathrm{CI}$ : $2.00-70.02 ; \mathrm{p}=0.007)$ and baseline $\%$ diameter of stenosis (DS) of SB (OR 1.07; 95\% CI: 1.02-1.13; $\mathrm{p}=0.012$ ) other independent predictors of SB deterioration, as assessed by angiography.

The mechanism of SB closure due to calcium has not been fully elucidated, but a higher risk of carina shift due to reduced compliance of the wall opposing the SB and a lower resistence encountered by the inflated balloon at the SB ostium could be a potential hypothesis. Carina is typically spared from atherosclerosis distribution owing to high local shear stress [13], but is the potential source of subsequent stent failure. Careful lesion preparation might therefore "soften" the lesion and reduce the risk of plaque shift (Table 2).

\section{Modifying balloons}

The cutting balloon has been available for almost 30 years. It is a semi-compliant balloon with three thin sharp blades mounted on its body, designed to cut the continuity of fibrocalcific plaque once the pressure of the balloon forces them against the vessel wall, creating fissures on the plaque.

The main drawback of these tools is their high rigidity that hinders system advancement and lesion negotiation through tortuous and calcified vessels [14]. Moreover, cutting balloon angioplasty showed a higher rate of coronary perforation $(0.8 \%$ vs. $0 \%, \mathrm{p}=0.03$ ) and had no advantages in terms of restenosis compared to balloon angioplasty ( $31 \%$ vs. $30 \%, p=N S$ ) [15]. Therefore, after the first optimistic feasibility reports [16], scoring the plaque to facilitate stent deployment has been reported only in occasional cases for treatment of calcified bifurcations. This technology has recently undergone some important revisions: in the newer generation of cutting balloons (Wolverine ${ }^{\mathrm{TM}}$ Cutting Balloon, Boston Scientific, USA), the atherotome's support thickness has been reduced, without affecting the functional height of the blade, resulting in an overall smaller crossing profile and improved crossability.

The principle of using a "buddy wire" to fracture calcified plaque [17] promoted the development of the scoring balloon: wires apposed externally to the body of the balloon increase local punctual pressure, achieving plaque fissuration [18].
Otsuka et al. [19] recently proposed that prolonged inflation might improve the success rate of these devices with a "creep phenomenon": a sustained tensile load produces microcrack formation and propagation leading to a phasic tissue elongation.

Scoring balloons are available in two different families, the first one is engineered as a traditional balloon with three segments of wire apposed spirally or linearly on the outer surface of the balloon; the second kind has only one external wire and is engineered as a rapid exchange balloon with a very short monorail involving only the tip of the balloon, thus allowing the guidewire to course along the balloon and to serve, together with the other, as a scoring wire. Scoring balloon, especially the latter has a better crossing profile than old generation cutting balloons but still has less deliverability than a standard balloon. Several reports suggest a very good success rate but many authors still consider these devices limited to a less-than-severely calcified lesion.

Using a provisional approach with a scoring balloon for the SB and a DES for the MV in "true" bifurcation lesions yielded promising results in a single arm prospective study, with a rate of crossover to stent deployment in the SB as low as $11 \%$, and a target lesion revascularization rate of 3.3\% [20].

\section{Atherectomy}

Rotational atherectomy (RA) (Rotablator, Boston Scientific-Scimed Corporation, Natick, Massachusetts), firstly introduced more than 30 years ago [21], is a plaque modification method achieved by a high-speed diamond chips-coated rotating burr that allows selective abrasion of calcified hard tissues. In the pre-stent era RA was conceived as a stand-alone approach to obtain plaque debulking in order to gain lumen diameter in a severely calcified lesion. It subsequently became evident that RA may offer its best contribution as a major "plaque modifier" for subsequent balloon angioplasty and stent implantation. Calcified ostial and bifurcating lesions were effectively treated by $\mathrm{RA}$ in the pre-stent era [22]. Its main effect is to restore adequate lumen by breaking the continuity of calcium plaque, increasing lesion "crossability" and making the artery more compliant to balloon dilatation.

Rotational atherectomy relies on two principles [23]:

- "Differential cutting" defines the ability to selectively ablate hard plaque components while 
Table 2. Features of the main plaque modifying devices.

\begin{tabular}{|c|c|c|c|}
\hline Device & Material & Technical features & Ref. \\
\hline $\begin{array}{l}\text { Focused force } \\
\text { dilatation balloon } \\
\left(\text { Scoreflex }^{\mathrm{TM}}\right)\end{array}$ & 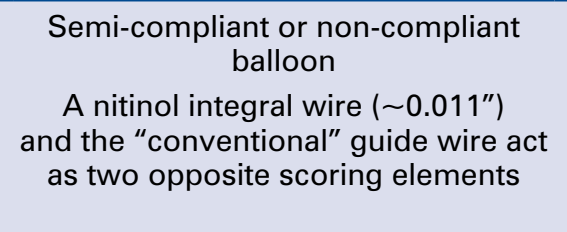 & $\begin{array}{c}\text { Balloon size } 2.0-4 \mathrm{~mm} \\
\text { Working range } 6-16 \mathrm{~atm} \\
\text { Crossing profile } 0.032^{\prime \prime} \mathrm{F} \\
\text { 5F Guiding catheter compatible } \\
\text { Guide wire } 0.014^{\prime \prime}\end{array}$ & {$[17]$} \\
\hline $\begin{array}{l}\text { Scoring balloon } \\
\text { (Angiosculpt }^{\circledR} \text { ) }\end{array}$ & $\begin{array}{l}\text { Semi-compliant balloon } \\
\text { Nitinol-enhanced balloon deflation } \\
\text { Electropolished, rectangular, spiral } \\
\text { scoring element }\left(\sim 0.005^{\prime \prime}\right)\end{array}$ & $\begin{array}{c}\text { Balloon size } 2.0-3.5 \mathrm{~mm} \\
\text { Working range } 2-20 \mathrm{~atm} \\
\text { Crossing profile } 0.047^{\prime \prime} \mathrm{F} \\
6 \mathrm{~F} \text { Guiding catheter } \\
\text { Guide wire } 0.014^{\prime \prime}\end{array}$ & {$[17,20]$} \\
\hline $\begin{array}{l}\text { Cutting } \\
\text { (Wolver }\end{array}$ & $\begin{array}{l}\text { Nylon non-compliant balloon } \\
\text { Microsurgical blade, called: "Ather- } \\
\text { otome" (functional height: } \sim 0.005^{\prime \prime} \text { ) }\end{array}$ & $\begin{array}{c}\text { Balloon size } 2.0-4.0 \mathrm{~mm} \\
\text { Working range } 8-16 \text { atm } \\
\text { Reduced crossing } \\
\text { profile then Flexotome } \\
\text { 5F Guiding catheter compatible }\end{array}$ & {$[16]$} \\
\hline $\begin{array}{l}\text { Rotational atherectomy } \\
\text { (Rotablator }^{\circledR} \text { ) }\end{array}$ & $\begin{array}{l}\text { Diamond-coated elliptical burr } \\
\text { rotating up to } 190,000 \mathrm{rpm}\end{array}$ & $\begin{array}{l}\text { Multiple burrs size }(1.25->2.5 \mathrm{~mm}) \\
\text { RotaWire }{ }^{\mathrm{TM}}\left(330 \mathrm{~cm}, 0.014^{\prime \prime},\right. \\
\text { extra support or floppy) } \\
\text { Catheter } 6-10 \mathrm{~F} \\
\text { (according to the size burr) }\end{array}$ & [23] \\
\hline $\begin{array}{l}\text { Orbital atherectomy } \\
\text { system } \\
\text { (Diamondback } 360^{\circledR} \text { ) } \\
\text { mammertum }\end{array}$ & $\begin{array}{c}\text { Eccentrically mounted diamond- } \\
\text {-coated crown }(1.25 \mathrm{~mm}) \text { rotating up } \\
\text { to } 200,000 \mathrm{rpm}\end{array}$ & $\begin{array}{c}\text { 6F Guiding catheter } \\
\text { ViperWire Advance }{ }^{\circledR} \\
\left(0.014^{\prime \prime}\right)\end{array}$ & $\begin{array}{c}{[27,28,} \\
29]\end{array}$ \\
\hline $\begin{array}{l}\text { Intravascular lithotripsy } \\
\left.\text { (Shockwave }{ }^{\circledR}\right)\end{array}$ & $\begin{array}{l}\text { Semi-compliant balloon containing } \\
\text { a series of unfocused, electrohydraulic } \\
\text { lithotripsy emitters }\end{array}$ & $\begin{array}{l}\text { Balloon size } 2.5-4 \mathrm{~mm} \\
\text { Inflated to } 4 \text { atm and } \\
\text { administered } 4 \text { cycles of } 10 \mathrm{~s} \\
\text { Crossing profile } 0.044^{\prime \prime} \\
\text { 6F Guiding catheter } \\
\text { Guide wire } 0.014^{\prime \prime}\end{array}$ & {$[36]$} \\
\hline
\end{tabular}

displacing and sparing soft tissues, that are deflected away. At rotational speeds $>60,000$ rpm the friction, which occurs when sliding surfaces are in contact, is virtually eliminated. The "differential cutting" should theoretically allow RA to accomplish a selective abrasion of plaque in the proximity of a branch, thus increasing the procedural success rate and reducing the need for side-branch intervention.

- "Orthogonal displacement of friction" refers to a change in effective longitudinal friction, which is almost eliminated, resulting in reduced surface drag and unimpeded advancement of the burr in tortuous and diseased segments of the coronary tree.

Rotablator ${ }^{\circledR}$ advances over a guidewire (Rotawire), is a $325 \mathrm{~cm}$ long and 0.009" thin shaft, with a $0.014 " 2.2 \mathrm{~cm}$ long floppy spring tip, which has a lower performance in crossing lesions and tortuosity than a traditional guidewire. Rotawire can therefore be positioned through a microcatheter after an exchange with a "workhorse" guidewire. 
The burr is mounted on a spiral drive shaft that is connected to an advancer and covered by a sheath.

The burr's passage through the lesion creates fragments with a diameter theoretically smaller than blood cells; such microparticles should easily cross microcirculation and then be eliminated by the reticuloendothelial system. Nevertheless, the no-reflow phenomenon has frequently been reported after RA-assisted PCI, and therefore the use of a flushing solution containing vasodilators such as calcium antagonists, nitrates or adenosine alone or in combination has been suggested [24]. A widely used solution to cool the Rotablator ${ }^{\circledR}$ turbine and to flush the coronary circulation from debris generated during the ablation is a saline solution with equal proportions of verapamil, nitrates, and heparin ( $5 \mathrm{mg} / 5 \mathrm{mg} / 5,000 \mathrm{U}$ in $500 \mathrm{~mL}$ of saline). The use of the Rotablator ${ }^{\circledast}$ is technically demanding and is associated with a significant incidence of adverse events. Among the procedural complications burr's lodging, coronary perforation, large dissection, acute thrombosis with abrupt coronary occlusion and atrioventricular-block have been reported. In order to minimize the complication rate, the EAPCI consensus document [25] recommends distal positioning of the Rotawire in order to have adequate support and stability and the use a rotational speed in the range of 135,000-180,000 rpm to obtain effective plaque modification, with a gentle picking to-and-fro movement of the burr, avoiding brisk deceleration (> 5,000 rpm) and to stop rotation when the burr is over the lesion to minimize the risk of lodgment. During RA procedures the increased quantity of injected contrast medium may cause deterioration of renal function. Therefore, all strategies useful to contain acute kidney injury should be applied [26], although there are no randomized trials exploring this issue.

Currently, as the role of RA has changed from debulking to plaque preparation, a burr-to-artery diameter ratio of $0.5-0.6$ (smaller than previously recommended 0.7 ) should be targeted in order to balance efficacy in lesion ablation and risk of coronary wall damage.

After several failures to cross the lesion, downsizing of the burr is recommended. In case the smallest burr does not pass, a change to a more supportive, or even a larger guiding catheter must be considered.

More recently, the Diamondback $360^{\circledast}$, a coronary orbital atherectomy system (OAS) has become available. Mechanism of OAS is a differential sanding to reduce plaque burden with a carboncoated crown $(1.25 \mathrm{~mm})$. Theoretically, softer tis- sue flexes away from the crown while fibrotic tissue or arterial calcium is engaged. A drive shaft with an eccentrically mounted diamond-coated crown provides proximal and distal sanding; the crown's orbital diameter expands radially via centrifugal force [27]. Operators can control the speed of rotation, with a higher speed creating a larger sanding diameter by increasing lateral pressure. Pivotal trials have documented safety and feasibility of OAS in preparation of severely calcified plaques before stent deployment [28, 29], although clinical evidence is still limited.

The interest in calcified lesion preparation was recently revived in the Comparison of Strategies to Prepare Severely Calcified Coronary Lesions (PREPARE-CALC) trial, where modifying balloons (cutting or scoring) were compared with RA, in the setting of stable coronary artery disease. Bifurcating lesion were present in $42 \%$ of cases. The trial showed a clear superiority in terms of procedural success in the RA group (98\% vs. $81 \%, \mathrm{p}<0.001)$, driven by a $20 \%$ of cross-over to RA, while, at 9 months, mean in-stent late lumen loss was similar in the two groups, as well as stent thrombosis $(0 \%$ in both groups) [30].

Plaque debulking in coronary bifurcation with any atherectomy device (both RA and OAS) may pose some technical challenges because of the need of single wire use, impeding the protection of side branches (Fig. 2). Reportedly, a tricky approach with a child-in-mother guiding catheter allowed $\mathrm{RA}$ with the use of multiple guidewires in order to protect side branches proximal to the target lesion and to gain more support [31].

As for calcified bifurcating lesions, there are several observational studies highlighting the safety and effectiveness of RA, that achieved a high $(>90 \%)$ success rate with a low rate of major adverse events (MACE $<5 \%$ ) and the need for bailout side-branch stenting $(<20 \%)[32,33]$. Recently, Chambers et al. [34], in a series of patients undergoing atherectomy with either OAS or RA for severely calcified plaques, documented similar low 30-day MACE rates among patients with bifurcation as compared with non-bifurcation lesions. OAS was associated with significantly shorter procedure and fluoroscopy time, as compared with RA.

\section{Lithoplasty}

Intravascular lithotripsy ( $\mathrm{IvL}$ ) is the most recent tool for the treatment of calcified lesion after being introduced in peripheral vascular angioplasty. IvL consists of a balloon catheter that uses sonic 


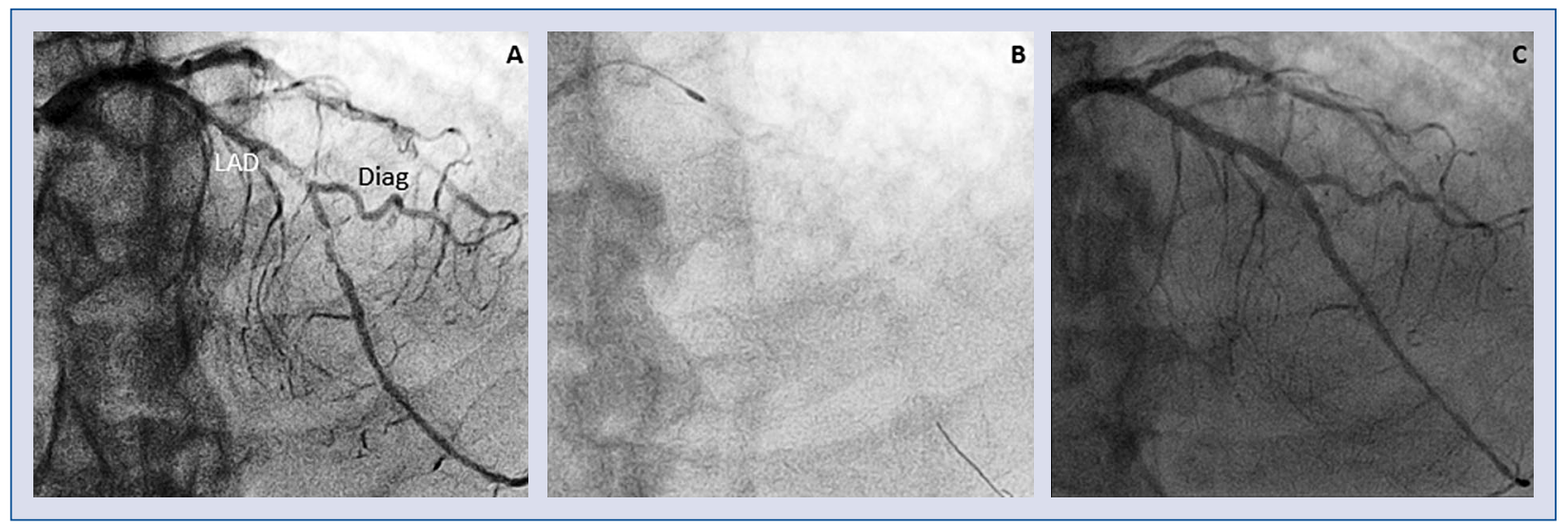

Figure 2. Coronary calcified bifurcating lesion treated by rotablator. Diffuse calcified atherosclerosis of left anterior descending artery (LAD) resulting in severe stenosis involving the bifurcation site of a large diagonal branch (Diag); A. Angiographic view; B. Rotawire positioned distally in the main branch with Rotablator burr approaching the lesion; C. final result after provisional stenting.

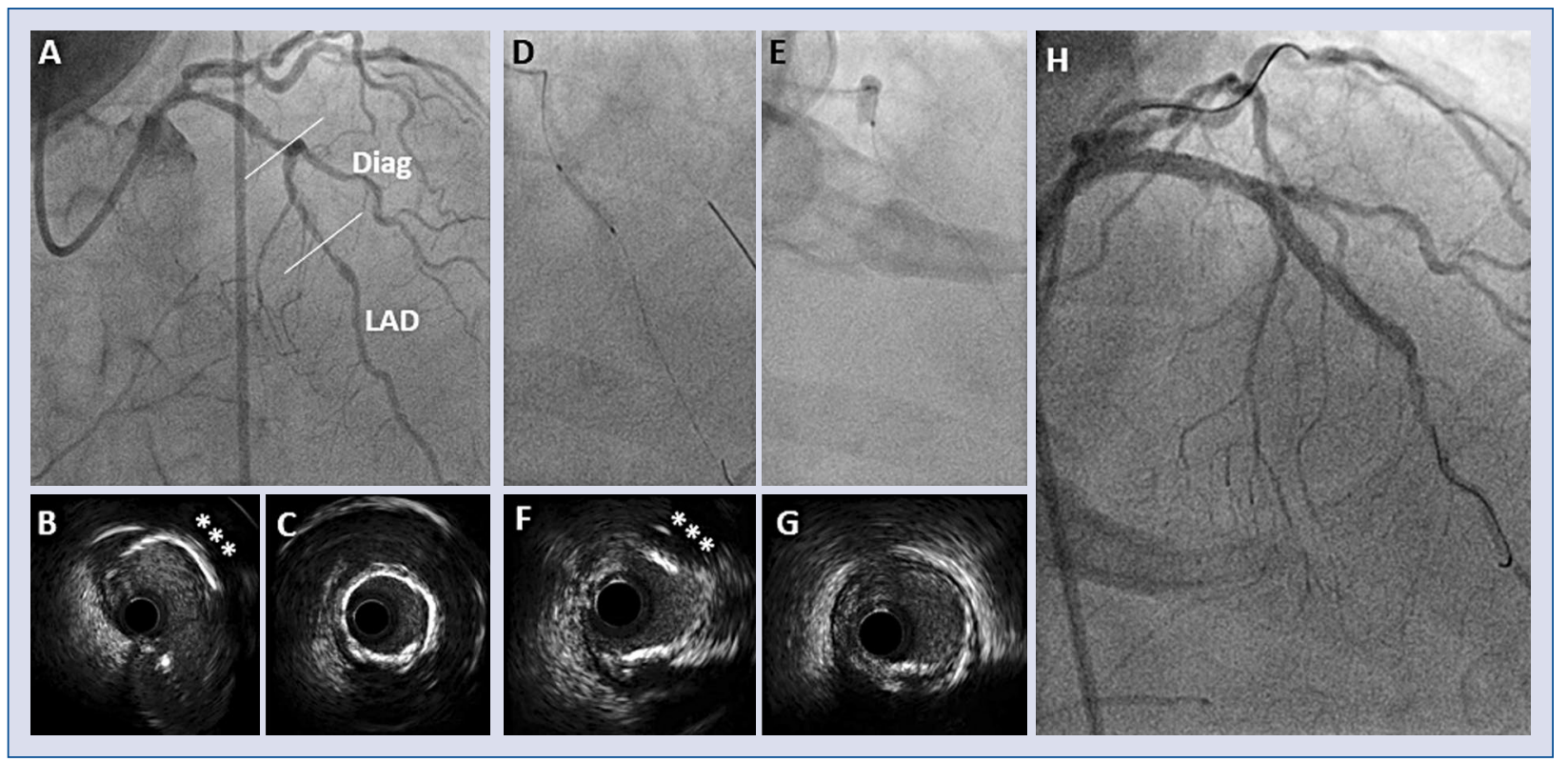

Figure 3. Coronary calcified bifurcating lesion treated by coronary lithotripsy. Long left anterior descending artery (LAD) lesion involving the bifurcation site of a large diagonal branch (Diag); A. Angiographic view; B. Intravascular ultrasound (IVUS) section at bifurcation site, with an eccentric calcific plaque (asterisks); C. IVUS section at mid LAD, with a concentric calcific plaque ("annular ring"); D, E. Intravascular lithotripsy (IVL) balloon inside of the lesions; F, G. IVUS section after IVL, showing effective disruption of the calcific plaques; H. Final angiographic view after $L A D$ stenting.

pulses to fracture calcified tissues with virtually no debris production. The concept of acoustic waves to selectively crack hard bodies has been employed in urology for decades. This approach aims to avoid the trauma produced by blades and burrs and their related risk, still offering an effective disruptive action on calcium (Fig. 3).
IvL device is composed of a $12 \mathrm{~mm}$ long balloon catheter with three emitters inside the balloon between two radiopaque markers; it has a profile smaller than other modifying balloons, quite comparable to a non-compliant balloon and is available in 7 sizes ranging from 2.5 to $4.0 \mathrm{~mm}$. An electrical discharge at the emitters vaporizes the 


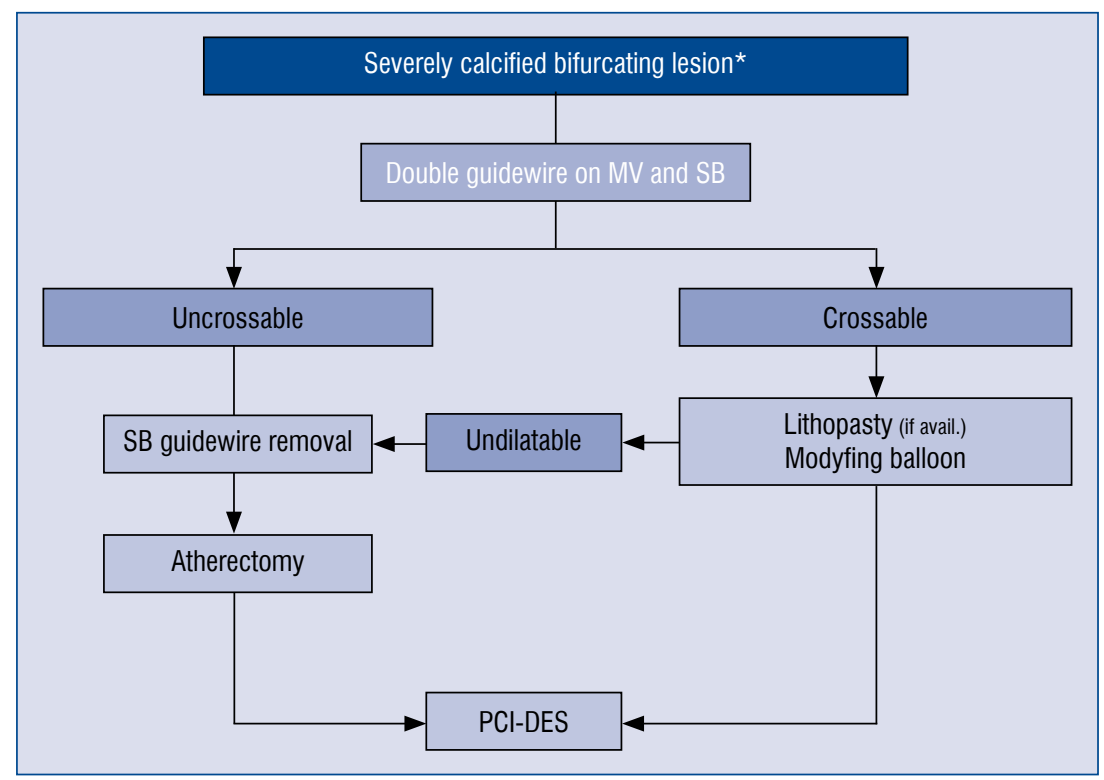

Figure 4. Proposed algorithm for the treatment of severely calcified bifurcating lesions; *Side branch longer than $73 \mathrm{~mm}$, with a diameter $\geq 2 \mathrm{~mm}$; GW - guidewire; MV — main vessel; SB — side branch; PCl-DES — percutaneous coronary intervention-drug-eluting stent.

fluid generating a series of sonic pulses that propagate and selectively interact with calcified plaques even in their inner adventitial layer. In the absence of any system mounted onto the balloon itself, the profile of IvL should guarantee better crossability than other modifying balloons, although in severely calcified lesions uncrossable by any balloon, atherectomy seems to stand as a last resource. In another way, unlike RA, IvL can be used with more than a guidewire to protect side branches; its effect might theoretically extend to calcified side branches ostia and, reportedly, it can be used with the kissing balloon technique because of the presumed ability of IvL to propagate across a second balloon. Moreover, IvL has been employed to fracture a calcified plaque outside an underexpanded stent, allowing appropriate stent expansion at subsequent high-pressure dilatation [35]. An OCT study [36] demonstrated that vessel preparation with IvL led to an increase in minimum lumen area and a reduction in area stenosis, allowing stents to be delivered into all target lesions, with an efficacy proportional with calcification severity, with a very low complication rate (no perforation, nor slow/no flow phenomenon). The prospective, multicenter, single arm Study "Disrupt CAD II", recently documented the safety and the effectiveness of IvL [37].

\section{Conclusions}

Percutaneous coronary intervention of a severely calcified bifurcating stenosis is a challenge due to the inherent risks related to inadequate stent expansion and side branch compromise. Therefore, adequate lesion preparation with dedicated tools is often required. Modifying balloons are effective in lesion preparation, but their use is undermined by low crossabilty. Atherectomy, has been available for 30 years only as rotational, more recently it has evolved as orbital, allowing a high success rate, with an increased complication rate as a trade-off. IvL are now promising devices that obtain calcific plaque fragmentation with sonic pulses locally delivered, but the clinical translation of such benefit is still to be determined.

Here we propose a practical algorithm for the treatment of severely calcified bifurcating lesions (Fig. 4); in crossable lesions, modifying balloons, scoring better than cutting, can be the first choice and now $\mathrm{IvL}$ is extremely promising. In case of crossing failure, atherectomy still stands as the last resource [38], but it requires SB removal.

Conflict of interest: None declared 


\section{References}

1. Grundeken MJ, Wykrzykowska JJ, Ishibashi Y, et al. First generation versus second generation drug-eluting stents for the treatment of bifurcations: 5-year follow-up of the LEADERS all-comers randomized trial. Catheter Cardiovasc Interv. 2016; 87(7): E248-E260, doi: 10.1002/ccd.26344, indexed in Pubmed: 26649651.

2. Lassen JF, Burzotta F, Banning AP, et al. Percutaneous coronary intervention for the left main stem and other bifurcation lesions: 12th consensus document from the European Bifurcation Club. EuroIntervention. 2018; 13(13): 1540-1553, doi: 10.4244/EIJD-17-00622, indexed in Pubmed: 29061550.

3. Zimarino M, Curzen N, Cicchitti V, et al. The adequacy of myocardial revascularization in patients with multivessel coronary artery disease. Int J Cardiol. 2013; 168(3): 1748-1757, doi: 10.1016/j.ijcard.2013.05.004, indexed in Pubmed: 23742927.

4. Fujino Y, Attizzani GF, Tahara S, et al. Impact of main-branch calcified plaque on side-branch stenosis in bifurcation stenting: an optical coherence tomography study. Int J Cardiol. 2014; 176(3): 1056-1060, doi: 10.1016/j.ijcard.2014.07.143, indexed in Pubmed: 25156838.

5. Kim HY, Doh JH, Lim HS, et al. Identification of coronary artery side branch supplying myocardial mass that may benefit from revascularization. JACC Cardiovasc Interv. 2017; 10(6): 571-581, doi: 10.1016/j.jcin.2016.11.033, indexed in Pubmed: 28259665.

6. Louvard Y, Medina A, Stankovic G. Definition and classification of bifurcation lesions and treatments. EuroIntervention. 2010; 6 Suppl J: J31-J35, doi: 10.4244/EIJV6SUPJA6, indexed in Pubmed: 21930488.

7. Zimarino M, Briguori C, Amat-Santos IJ, et al. Mid-term outcomes after percutaneous interventions in coronary bifurcations. Int J Cardiol. 2019; 283: 78-83, doi: 10.1016/j.ijcard.2018.11.139, indexed in Pubmed: 30528620.

8. Mintz GS, Lefèvre T, Lassen JF, et al. Intravascular ultrasound in the evaluation and treatment of left main coronary artery disease: a consensus statement from the European Bifurcation Club. EuroIntervention. 2018; 14(4): e467-e474, doi: 10.4244/ /EIJ-D-18-00194, indexed in Pubmed: 29688182.

9. Neumann F, Sousa-Uva M, Ahlsson A, et al. 2018 ESC/EACTS Guidelines on myocardial revascularization. Kardiol Pol. 2018: 1585-1664, doi: 10.5603/kp.2018.0228.

10. Madhavan MV, Tarigopula M, Mintz GS, et al. Coronary artery calcification: pathogenesis and prognostic implications. J Am Coll Cardiol. 2014; 63(17): 1703-1714, doi: 10.1016/j. jacc.2014.01.017, indexed in Pubmed: 24530667.

11. Bourantas CV, Zhang YJ, Garg S, et al. Prognostic implications of coronary calcification in patients with obstructive coronary artery disease treated by percutaneous coronary intervention: a patient-level pooled analysis of 7 contemporary stent trials. Heart. 2014; 100(15): 1158-1164, doi: 10.1136/heartjnl-2013-305180, indexed in Pubmed: 24846971.

12. Latib A, Takagi K, Chizzola G, et al. Excimer Laser LEsion modification to expand non-dilatable stents: the ELLEMENT registry. Cardiovasc Revasc Med. 2014; 15(1): 8-12, doi: 10.1016/j.carrev.2013.10.005, indexed in Pubmed: 24290659.

13. Pescetelli I, Zimarino M, Ghirarduzzi A, et al. Localizing factors in atherosclerosis. J Cardiovasc Med (Hagerstown). 2015; 16(12): 824-830, doi: 10.2459/JCM.0000000000000224, indexed in Pubmed: 25575274.
14. Barath P, Fishbein MC, Vari S, et al. Cutting balloon: a novel approach to percutaneous angioplasty. Am J Cardiol. 1991; 68(11): 1249-1252, doi: 10.1016/0002-9149(91)90207-2, indexed in Pubmed: 1842213.

15. Mauri L, Bonan R, Weiner BH, et al. Cutting balloon angioplasty for the prevention of restenosis: results of the cutting balloon global randomized trial. Am J Cardiol. 2002; 90(10): 1079-1083, doi: 10.1016/s0002-9149(02)02773-x, indexed in Pubmed: 12423707.

16. Dahm JB, Dörr M, Scholz E, et al. Cutting-balloon angioplasty effectively facilitates the interventional procedure and leads to a low rate of recurrent stenosis in ostial bifurcation coronary lesions: A subgroup analysis of the NICECUT multicenter registry. Int J Cardiol. 2008; 124(3): 345-350, doi: 10.1016/j. ijcard.2007.02.014, indexed in Pubmed: 17434613.

17. Hussain F, Kashour T, Rajaram M. Ostial RCA intervention: guiding catheter challenges and use of a buddy wire to perform focused-force angioplasty on a severely calcific ostial right coronary lesion. J Invasive Cardiol. 2006; 18(12): E298-E301, indexed in Pubmed: 17197719.

18. Jujo K, Saito K, Ishida I, et al. Intimal disruption affects drugeluting cobalt-chromium stent expansion: A randomized trial comparing scoring and conventional balloon predilation. Int J Cardiol. 2016; 221: 23-31, doi: 10.1016/j.ijcard.2016.07.002, indexed in Pubmed: 27400292.

19. Otsuka Y, Koyama T, Imoto Y, et al. Prolonged inflation technique using a scoring balloon for severe calcified lesion. Int Heart J. 2017; 58(6): 982-987, doi: 10.1536/ihj.16-605, indexed in Pubmed: 29162780.

20. Weisz G, Metzger DC, Liberman HA, et al. A provisional strategy for treating true bifurcation lesions employing a scoring balloon for the side branch: final results of the AGILITY trial. Catheter Cardiovasc Interv. 2013; 82(3): 352-359, doi: 10.1002/ /ccd.24630, indexed in Pubmed: 22927100.

21. Ritchie JL, Hansen DD, Intlekofer MJ, et al. Rotational approaches to atherectomy and thrombectomy. Z Kardiol. 1987; 76 Suppl 6: 59-65, indexed in Pubmed: 3439260.

22. Zimarino M, Corcos T, Favereau X, et al. Rotational coronary atherectomy with adjunctive balloon angioplasty for the treatment of ostial lesions. Cathet Cardiovasc Diagn. 1994; 33(1): 22-27, doi: 10.1002/ccd.1810330106, indexed in Pubmed: 8001097.

23. Cavusoglu E, Kini AS, Marmur JD, et al. Current status of rotational atherectomy. Catheter Cardiovasc Interv. 2004; 62(4): 485-498, doi: 10.1002/ccd.20081, indexed in Pubmed: 15274159.

24. Cohen BM, Weber VJ, Blum RR, et al. Cocktail attenuation of rotational ablation flow effects (CARAFE) study: pilot. Cathet Cardiovasc Diagn. 1996; Suppl 3: 69-72, indexed in Pubmed: 8874932.

25. Barbato E, Carrié D, Dardas P, et al. European expert consensus on rotational atherectomy. EuroIntervention. 2015; 11(1): 30-36, doi: 10.4244/EIJV11I1A6, indexed in Pubmed: 25982648.

26. Ando G, Cortese B, Russo F, et al. Acute Kidney Injury After Radial or Femoral Access for Invasive Acute Coronary Syndrome Management: AKI-MATRIX. J Am Coll Cardiol. 2017.

27. Kini AS, Vengrenyuk Y, Pena J, et al. Optical coherence tomography assessment of the mechanistic effects of rotational and orbital atherectomy in severely calcified coronary lesions. Catheter Cardiovasc Interv. 2015; 86(6): 1024-1032, doi: 10.1002/ /ccd.26000, indexed in Pubmed: 25964009.

28. Chambers JW, Feldman RL, Himmelstein SI, et al. Pivotal trial to evaluate the safety and efficacy of the orbital atherectomy system 
in treating de novo, severely calcified coronary lesions (ORBIT II). JACC Cardiovasc Interv. 2014; 7(5): 510-518, doi: 10.1016/j. jcin.2014.01.158, indexed in Pubmed: 24852804.

29. Bhatt P, Parikh P, Patel A, et al. Long-term safety and performance of the orbital atherectomy system for treating calcified coronary artery lesions: 5-Year follow-up in the ORBIT I trial. Cardiovasc Revasc Med. 2015; 16(4): 213-216, doi: 10.1016/j. carrev.2015.03.007, indexed in Pubmed: 25866032.

30. Abdel-Wahab M, Toelg R, Byrne RA, et al. High-Speed rotational atherectomy versus modified balloons prior to drug-eluting stent implantation in severely calcified coronary lesions. Circ Cardiovasc Interv. 2018; 11(10): e007415, doi: 10.1161/CIRCINTERVENTIONS.118.007415, indexed in Pubmed: 30354632.

31. Iannaccone $\mathrm{M}$, Colangelo S, Di Mario $\mathrm{C}$, et al. Double wire rotational atherectomy technique in a heavily calcified coronary bifurcation. EuroIntervention. 2018; 14(2): 204-205, doi: 10.4244/ /EIJ-D-18-00001, indexed in Pubmed: 29437038.

32. Ito H, Piel S, Das P, et al. Long-term outcomes of plaque debulking with rotational atherectomy in side-branch ostial lesions to treat bifurcation coronary disease. J Invasive Cardiol. 2009; 21(11): 598-601, indexed in Pubmed: 19901416.

33. Iannaccone M, Barbero U, D'ascenzo F, et al. Rotational atherectomy in very long lesions: Results for the ROTATE regis- try. Catheter Cardiovasc Interv. 2016; 88(6): E164-E172, doi: 10.1002/ccd.26548, indexed in Pubmed: 27083771.

34. Chambers JW, Warner C, Cortez J, et al. Outcomes after atherectomy treatment of severely calcified coronary bifurcation lesions: a single center experience. Cardiovasc Revasc Med. 2019; 20(7): 569-572, doi: 10.1016/j.carrev.2018.08.017, indexed in Pubmed: 30201481.

35. Tovar Forero MN, Wilschut J, Van Mieghem NM, et al. Coronary lithoplasty: a novel treatment for stent underexpansion. Eur Heart J. 2019; 40(2): 221, doi: 10.1093/eurhearti/ehy593, indexed in Pubmed: 30289452.

36. Ali ZA, Brinton TJ, Hill JM, et al. Optical coherence tomography characterization of coronary lithoplasty for treatment of calcified lesions: first description. JACC Cardiovasc Imaging. 2017; 10(8): 897-906, doi: 10.1016/j.jcmg.2017.05.012, indexed in Pubmed: 28797412.

37. Ali ZA, Nef H, Escaned J, et al. Safety and effectiveness of coronary intravascular lithotripsy for treatment of severely calcified coronary stenoses. The Disrupt CAD II Study. Circ Cardiovasc Interv. 2019; 12: e008434.

38. Zimarino M, Corcos T, Bramucci E, et al. Rotational atherectomy: A "survivor" in the drug-eluting stent era. Cardiovasc Revasc Med. 2012; 13(3): 185-192, doi: 10.1016/j.carrev.2012.03.002, indexed in Pubmed: 22522057. 